\title{
Impact of Urban Environment on Students' Daily Rhythms and Sleep Patterns
}

\author{
Elena A. Piven ${ }^{1}$, Nikolay P. Piven ${ }^{2}$, and Nikolay N. Bushuev ${ }^{3}$ \\ ${ }^{1}$ RUDN-University, Ecological Faculty, 117198 Miklukho-Maklaya st. 6, Moscow, Russia \\ ${ }^{2}$ Pirogov Russian National Research Medical University, 117513 Moscow, Russia \\ ${ }^{3}$ Bauman Moscow State Technical University, 105005 Moscow, Russia
}

\begin{abstract}
This article presents the results of a research of the sleep patterns of 200 students living in dormitories in Moscow. The average duration of night sleep in the surveyed group was $6 \mathrm{~h} 37 \mathrm{~min}$. The proportion of students satisfied with the duration of night sleep was $36.5 \%$. Daily activity rhythms, in particular, the going to sleep and awakening time at the same time, are compiled by $47.5 \%$ of the surveyed students. $86.5 \%$ of students go to bed after midnight. The most late going to sleep time is observed among students of the 1 st and $4^{\text {th }}$ years. $37 \%$ of students suffer from insomnia, which is most often caused by stress and work in extracurricular time. It was found that the best indicators of well-being and learning ability were observed at night sleep duration from 6 to 8 hours. When the duration of night sleep is less than 6 hours, there was a deterioration in the state of students' health, wellbeing and learning ability. It was revealed that $92.2 \%$ of students who fall ill three or more times a year have a night sleep duration of less than 6 hours.
\end{abstract}

\section{Introduction}

In our century of rapid development of scientific and technological progress in an urban environment, information and mental overloads are increasing, while biological processes in the human body are changing very slowly. Urbanization with its increasing psycho-emotional loads is related to the restructuring of the organism of young students, a violation of circadian rhythm, based on genetically determined metabolism and biochemical cycles. In urban activities related to mental loads, longer working hours are required by reducing rest periods. At the same time, the shortage of time constantly continues to be felt, while the whole complex of human daily rhythms has a strict order, which ensures a stable internal synchronization of circadian rhythms [1-3].

University students are characterized by high mental loads, sharp changes of habitual way of life, formation of interpersonal relations outside the family, necessity of adaptation to new working, living and nutritive conditions, which allows classifying them to the group of significant risk of disease development [1-3]. They are developing a new, more intense daily rhythm, which includes preparation for classes, attendance of extracurricular student events, part-time work in the night shift. The formation of the daily rhythm is influenced by the experience of living in a dormitory, freedom from parental care. All of this can lead to serious sleep disturbances, and consequently to a decrease in student performance and a number of serious diseases [3-5]. Students need sufficient duration and quality of sleep due to high 
academic and psycho-emotional loads. It is known that without good sleep there can be no good waking [5-7].

There has been insufficient comprehensive research to assess the sleep patterns of students living in dormitories in large metropolitan cities; little research has been done on the factors that influence the duration of sleep and its impact on post-wake-up well-being. Therefore, the topic of the presented work is relevant and of great scientific and practical importance.

\section{Objective}

The objective of the work was to reveal the peculiarities of the sleep pattern of students of universities living in dormitories of a large metropolitan cities (the case of Moscow), associated with the impact of urban environment.

\section{Research Method}

A set of modern methods was used to achieve this goal: directional selection, sampling method, stratified sampling, survey (questionnaires), mathematically deductive and analytical methods. The target of the research is a random sampling of 100 female and 100 male students of universities who live in dormitories in Moscow.

\section{Results and Discussion}

In the sample we studied, the average age of students living in hostels is 21.3 years. The proportion of students in the $18-20$ age range was $41.5 \%, 31.5 \%$ in the $21-23$ years old range, $23.5 \%$ in the $24-26$ years old range, and $3.5 \%$ in the 17 years old range.

It is established that $23.5 \%$ of students were freshmen, $20 \%$ were second year students, $15 \%$ were third year students, $30 \%$ were fourth year students, and $11.5 \%$ were holders of Master's degree. The most part of the samples studied during the statistical analysis was for the 4 th year students.

The recommended amount of night sleep for students is 7.5-8 hours per day, as the negative impact of inadequate sleep on their academic performance and health has been proven [3-5]. Among people in the survey, the average duration of night sleep was $6 \mathrm{~h} 37 \mathrm{~min}$. At the same time, $81.5 \%$ of students have night sleep duration ranging from 5 to 8 hours.

The duration of night sleep for students living in dormitories, which was less than 5 hours, was revealed in $8.5 \%$ of respondents, in the range of 5-6 hours $-31.5 \%$, 6-7 hours $-25 \%$, $7-8$ hours $-25 \%$ and more than 8 hours $-10 \%$.

Depending on the length of the night sleep, the feeling of well-being of the young students also changed. With sleep duration less than 5 hours, $85 \%$ of students were found to be less attentive, sleepy and irritable, and only $15 \%$ of respondents did not notice any changes in their well-being and learning ability during the day. With sleep duration from 5 to 6 hours, the percentage of respondents who did not note any changes in their well-being and learning ability was $17.5 \%$. While the duration of night sleep increased to 6-7 hours, there was a sharp increase in the proportion of students with good health and learning ability which amounted to $58 \%$. At the same time, the best learning and well-being indicators were recorded for night sleep between seven and eight hours, and they were found in $68 \%$ of the surveyed students. It has been established that if the duration of night sleep exceeds eight hours, the number of students with no learning and well-being problems is reduced to $40 \%$. Thus, taking into account learning and well-being during the day, the optimal duration of night sleep for students should be between six and eight hours. 
The proportion of students satisfied with the duration of night sleep was $36.5 \%$, while $63.5 \%$ of students said that sleep was not enough. The highest number of students with less than 6 hours of night sleep is observed among 1st and 4th year students.

Following the sleep pattern (falling asleep and waking up at the same time) is the most important condition for quality sleep. The optimal bed time is 10-11 p.m., and the best time to wake up in the morning is 6-7 a.m.

We studied the question of bed time. It is established that $10-11$ p.m. $5 \%$ of students go to bed, at 11 p.m. $-8.5 \%$, from 00 a.m. to 01 a.m. $-38.5 \%$, from 01 a.m. to 02 a.m. $-20 \%$, and after 02 a.m., $28 \%$ of students. From this data it follows that students most often go to bed after midnight. The latest bed time is observed among 1st and 4th year students.

When studying student wake-up time, it was found that $5 \%$ of students wake up before 6 a.m., $11.5 \%$ wake up at 6-7 a.m., $36.5 \%$ wake up at 7-8 a.m., $32 \%$ wake up at 8-9 a.m., $6.5 \%$ wake up at 9-10 a.m. and $8.5 \%$ wake up after 10 a.m. $72 \%$ of students felt languid and drowsy when waking up, and $28 \%$ felt well and active.

The analysis of the morning wake-up time of the students depending on the time of leaving the dormitories to classes was carried out. The data showed that $31.5 \%$ of students wake up more than 1 hour before leaving the dorms, $28.5 \%$ wake up less than 30 minutes before leaving, and $40 \%$ wake up 30-60 minutes before leaving. At the same time, $33.5 \%$ of students have time to have breakfast, clean up and get ready, while $66.4 \%$ do not have time.

It should be noted that $47.5 \%$ of the surveyed students go to bed and wake up at the same time, while $52.5 \%$ do not do that.

One of the most important sleep problems is how long does it take to fall asleep. The research found that $20 \%$ of students fall asleep depending on their roommates, while $6.5 \%$ of those surveyed are not able to fall asleep for an hour or more, $36.5 \%$ fall asleep for no more than 30 minutes, and $37 \%$ fall asleep immediately. Answering the questionnaire on whether neighbors hinder the quality of sleep, $32 \%$ of students said yes.

Recently, a big problem has become the long stay of young people at the computer and TV before going to sleep. Thus, in our survey only $11.5 \%$ of respondents said that they rarely watch TV and use a computer before going to bed. Less than one hour before going to bed $20 \%$ of students spend in front of the computer and TV. More than $68.5 \%$ of students spend more than one hour in front of the computer and watching TV before going to bed, $33.6 \%$ of students go to bed between 00-01 a.m., and $66.4 \%$ later than 01 a.m.

It should be noted that only a small proportion of students who rarely watch TV and do not work on the computer before going to bed or spend less than 1 hour in front of them, go to bed around 11:00 p.m.

Hard mental work should be stopped more than one hour before going to sleep. We analyzed the students' stay in front of the computer and the time when they finished their mental work before going to sleep. It was found that $8.5 \%$ of students who rarely watch TV and do not use a computer before going to bed finished their mental work 30-60 minutes before going to sleep, and $3 \%-1$ hour or more. Among students who spend less than one hour in front of a computer and watching TV, $10 \%$ of those surveyed finish their mental work 30-60 minutes before going to sleep, and another $10 \%$ more than 1 hour before going to sleep. Among students who spend more than one hour before going to sleep in front of a computer and TV, $39.5 \%$ finish their mental work 30-60 minutes before going to sleep, and $29 \%$ finish it 1 hour or more.

In general, among the group of students $58 \%$ finish their mental work 30-60 minutes before going to sleep, and $42 \%$ finish it 1 hour or more. At the same time, there is a clear correlation between students staying in front of the computer and TV and the end of their mental work. Thus, the more time students spend in front of the computer and TV, the less they rest from mental work before going to sleep. Mental work performed just before bed 
makes it difficult to fall asleep, leads to contextual dreams, languor, and feeling ill after awakening [4-6].

The study examined sleep disorder problems. It was found that only $63 \%$ of students do not suffer from insomnia, $15 \%$ often suffer from insomnia, and $22 \%$ rarely suffer from it. Among students, who often suffer from insomnia, $66.7 \%$ of those surveyed had stress as a cause, $20 \%$ had work outside school hours, and the remaining $13.3 \%$ had no reasons. Among students with a rare manifestation of insomnia, the most frequent causes are stress $-54.6 \%$ of students, studies $-6.8 \%$ of students, work outside school hours $-11.3 \%$, and $27.3 \%$ - the cause is not identified.

Fresh air favours fast falling asleep, good sleep and a pleasant waking up. Only $40 \%$ of students follow hygienic guidelines and air the room before going to bed.

In assessing food intake, $21.5 \%$ of students had dinner more than 3 hours before bed, $16.5 \%$ had dinner 2-3 hours, 36.5\% had dinner 1-2 hours, $17 \%$ had dinner 30-60 minutes and $8.5 \%$ had dinner less than 30 minutes before going to bed. Thus, students most often eat dinner 1-2 hours before going to bed at the recommended mealtime, i.e. no later than 2-3 hours before going to bed.

Morning exercises play an important role in a person's health and well-being. It is established that $3.5 \%$ of students do morning exercises within 10 minutes, $20 \%$ within 1-5 minutes, and $76.5 \%$ do not do exercises. After a ten-minute morning exercise, all students felt active and good all day long. Among the students who did morning exercises for 1-5 minutes, $50 \%$ were languid, reduced concentration and paid less attention, and $50 \%$ were cheerful and active during the day. Among students who did not do exercises, $41 \%$ were cheerful, while the remaining $59 \%$ were languid, decreased concentration and paid less attention.

Violation of daily rhythms can lead to overfatigue and adversely affect health, weaken immunity and promote frequent colds, lead to somatic pathology [1-4, 6]. In a subjective assessment of their health, $85.5 \%$ of respondents consider themselves to be healthy, while $14.5 \%$ do not consider themselves to be, with $62 \%$ of the last group of students surveyed having a night sleep of less than 6 hours.

Chronic diseases are noted by $8.5 \%$ of students, $73.5 \%$ of students do not suffer from them and $18 \%$ do not know the objective information and it is difficult to answer the questionnaire due to lack of time for medical examination. Three or more times a year, $32 \%$ of those surveyed had colds, $30.5 \%$ had them twice a year, and $37.5 \%$ of students had them once a year or less. At the same time, $92.2 \%$ of students who fall ill three or more times a year have less than 6 hours of night sleep.

Most of the students surveyed $(91.5 \%)$ believe that good sleep supports health and is an important part of a healthy lifestyle.

\section{Conclusion}

A study of 200 students living in dormitories of a large city was conducted. The average sleep duration of the those surveyed was $6 \mathrm{~h} 37 \mathrm{~min} .63 .5 \%$ of students consider their night sleep insufficient in duration. The best learning and well-being indicators were found when $68 \%$ of the surveyed students had a night sleep between 7 and 8 hours. Most students $(86.5 \%)$ go to bed after midnight. The latest time to fall asleep is observed in 1st and 4th year students. At the same time, only $33.5 \%$ of students have time to have breakfast, clean up and get ready, while $66.4 \%$ do not have time to do that. Only $47.5 \%$ of students go to bed and wake up at the same time, while $52.5 \%$ do not do that. In this research, $20 \%$ of students falling asleep time depends on their roommates, $36.5 \%$ falling asleep time does not exceed 30 minutes, and $37 \%$ fall asleep immediately. Roommates affect $32 \%$ of students' sleep quality. 
$37 \%$ of students suffer from insomnia. The most frequent causes of insomnia are stress, work outside school hours and study, while in some cases the cause of insomnia is not identified. Among the surveyed students, $58 \%$ finish their mental work 30-60 minutes before going to bed, which may adversely affect the quality of sleep, and $42 \%-1$ hour or more. A clear correlation between students' stay in front of the computer and the end of their mental work before going to bed has been revealed. So, the more students spend time in front of the computer, the less time they have to rest before going to bed.

Spending more than one hour before going to bed in front of the computer and watching TV is noted by $68.5 \%$ of students, $33.6 \%$ of whom go to bed between $00-01$ a.m., and $66.4 \%$ after 01 a.m. Only $40 \%$ of students follow hygienic guidelines and ventilate the room before going to bed. Most often, students (36.5\%) have dinner 1-2 hours before they go to bed with an optimal last meal time not later than 2-3 hours before they go to bed.

It was found that $76.5 \%$ of students did not do morning exercises, while students who did a ten-minute morning exercise felt active and good all day long. $91.5 \%$ of students believe that a properly organized and adequate sleep is necessary to keep fit.

Sleep for students is a universal way to optimize human daily rhythms. It is necessary to keep fit and have good academic achievements.

\section{References}

1. A.I. Almojali, S.A. Almalki, A.S. Alothman, E.M. Masuadi, M.K. Alaqeel, J. of Epidemiology and Global Health. 2017 Sep;7(3):169-174.

2. G. Benham, Sleep Health. 2019 Dec; 5(6): 587-591.

3. S.P. Becker, M.A. Jarrett, A.M. Luebbe, A.A. Garner, G.L. Burns, M.J. Kofler, Sleep Health. 2018 Apr; 4(2):174-181.

4. L.K. Suen, K.L. Hon, W.W. Tam. Chronobiology international. 2008 Sep; 25(5): 760775.

5. M.E. Hartmann, J.R. Prichard. Sleep Health. 2018 Oct; 4(5): 463-471.

6. M.C. Azad, K. Fraser, N. Rumana, A.F. Abdullah, N. Shahana, P.J. Hanly, T.C. Turin. J. of clinical sleep medicine. 2015 Jan; 11(1): 69-74.

7. E.A. Piven, D.A. Breusov. RUDN J. of Medicine. 2017 Jan; 21(1): 127-136. 